IZA DP No. 4315

Symbolic Values, Value Formation and Interpersonal Relations

Giacomo Corneo

July 2009 


\title{
Symbolic Values, Value Formation and Interpersonal Relations
}

\author{
Giacomo Corneo \\ Free University of Berlin, \\ CEPR, CESifo and IZA
}

Discussion Paper No. 4315

July 2009

\author{
IZA \\ P.O. Box 7240 \\ 53072 Bonn \\ Germany
}

Phone: +49-228-3894-0

Fax: +49-228-3894-180

E-mail: iza@iza.org

Any opinions expressed here are those of the author(s) and not those of IZA. Research published in this series may include views on policy, but the institute itself takes no institutional policy positions.

The Institute for the Study of Labor (IZA) in Bonn is a local and virtual international research center and a place of communication between science, politics and business. IZA is an independent nonprofit organization supported by Deutsche Post Foundation. The center is associated with the University of Bonn and offers a stimulating research environment through its international network, workshops and conferences, data service, project support, research visits and doctoral program. IZA engages in (i) original and internationally competitive research in all fields of labor economics, (ii) development of policy concepts, and (iii) dissemination of research results and concepts to the interested public.

IZA Discussion Papers often represent preliminary work and are circulated to encourage discussion. Citation of such a paper should account for its provisional character. A revised version may be available directly from the author. 
IZA Discussion Paper No. 4315

July 2009

\begin{abstract}

\section{Symbolic Values, Value Formation and Interpersonal Relations}

Interpersonal relations are shaped by the judgements associated with the social categories that individuals perceive in their social contacts. I develop a model of how those judgments form based on a theory of symbolic values. The model depicts the interaction between two values, one associated with an inherited ethnic trait ("nationality") and one with an endogenous achievement trait ("income"). Individuals who are less likely to achieve are predicted to invest more value on nationalism and to have hostile relations with immigrants. Multiple equilibria are possible and better schooling may eliminate equilibria with xenophobia. Econometric findings from three large surveys corroborate the predictions derived from the theoretical model.
\end{abstract}

JEL Classification: Z1

Keywords: nationalism, immigration, interpersonal relations, value systems

Corresponding author:

Giacomo Corneo

Department of Economics

FU Berlin

Boltzmannstr. 20

14195 Berlin

Germany

E-mail: giacomo.corneo@fu-berlin.de

\footnotetext{
* Text prepared for a keynote lecture delivered at the conference "Happiness and relational goods: Well-being and interpersonal relations in the economic sphere" in Venice, June 12, 2009. I thank Holger Lüthen and Frank Neher for excellent research assistance.
} 


\section{Introduction}

Interpersonal relations have an idiosyncratic and a common component. On the one hand, any interpersonal relation is the product of a unique history of interactions between concrete human beings and of their memories of that history. On the other hand, interpersonal relations unfold in a socially constructed mental frame: individuals encounter each other as carriers of traits whose saliency and meaning are to a large extent socially determined. People first meet as men and women, white and black, subordinate and boss, and only after - if their communication deepens - as individualized persons. First encounters ${ }^{1}$ are governed by the expectations and judgements associated with the social categories - like gender, race, and occupation - that individuals perceive in their social contacts. Those judgements heavily affect the utility derived from interpersonal relations. They may determine whether a first encounter begins with a smile or with raised eyebrows, with deference or disdain, with a handshake or an erected finger. And the quality of a first encounter may determine whether the relation continues and on which track. Since social judgments carry such heavy consequences, people's search for personal contacts as well as their efforts to avoid them, along with the resulting network of relations, depend on the prevailing stereotypes associated with social categories.

What drives people's evaluation of social categories? The formation of values and attitudes is the object of longstanding lines of research in sociology, psychology, anthropology and even biology. Economic analysis based on the traditional rational-choice paradigm can contribute novel insights into those issues and thereby enrich our understanding of economic phenomena like the accumulation of human capital, the persistence of inequality, and long-run growth. To substantiate that claim, I will first sketch the main ideas of a theory of symbolic values that was proposed by Corneo and Jeanne (2009a, 2009b). That theory offers an economic perspective on value formation and can be utilized to study the social determination of interpersonal relations. Based on it, I will then develop a model of the relations between two different ethnic groups in a country: natives and immigrants. That model offers an explanation for the existence of xenophobia and for its interplay with the ability to invest in human capital. Finally, the model's predictions will be confronted with empirical evidence obtained from three large representative surveys.

\footnotetext{
${ }^{1}$ Gui (2005) introduced this terminology to describe those peculiar acts of production and consumption that characterize interpersonal relations from an economic viewpoint.
} 


\section{Theory of symbolic values}

Some personal characteristics, like nationality and professional activity, seem to be invested with symbolic values by human beings. These values determine the esteem that individuals receive from other people as well as their self-esteem. Those values are symbolic in the sense that they are immaterial: they affect the well-being of individuals - so they are values - but without affecting their consumption of material goods - so they are symbolic.

A system of symbolic values is a set of judgments about salient characteristics. The theory of symbolic values aims at explaining the variation of those judgments across social groups and single individuals. For instance, individuals in a given country may attach a very different value to descending from an aristocratic family or to being divorced. They may attach a different value to tax evasion: an individual may view it as immoral, another one may view it as just clever. Endorsed symbolic values determine how one feels when having those salient characteristics and how one behaves towards those who have those characteristics.

The theory of symbolic values is based on four main assumptions:

1) Evaluative attitude. Individuals pass judgments of approval, admiration, etc., and their opposite upon certain traits, acts, and outcomes.

Those judgements are determined by an individual's value system, which is a way to allocate value to bundles of judgeable characteristics. Formally, the value system of an individual is a function that maps an exogenous set of judgeable types onto the real line.

2) Social approbativeness. Individuals desire a good opinion of oneself on the part of other people.

The relevant human environment for approbativeness may be an individual's family, friends, colleagues, neighbors, or society at large. The desired ways of thinking may be in a scale that distinguishes contempt, indifference, interest, approval, praise, admiration, and veneration.

3) Self-approbativeness. Individuals have a desire for self-esteem.

This desire for a pleasing idea of oneself presupposes self-consciousness. Humans are both actors and spectators of what they do. Since they are evaluative beings, they also judge themselves.

4) Consistency. The standards of approbation or disapprobation which the individual applies to himself are the same as those which he applies to other people.

This postulate corresponds to the rule of judging yourself as you would judge of others. While psychologists have identified ways of self-deception, in the main individuals are subject to the control by the logic of consistency. It is difficult to systematically approve 
in oneself acts which one condemns in others, and when one does so, his fellows are quick to point out the inconsistency.

Value systems arise within various socialization structures. Symbolic values are transmitted in a cultural process by agencies of socialization like the family, the peers, and the media. Parents are a main agency of socialization and the theory of symbolic values has been utilized to study how altruistic parents socialize their children in various contexts.

The study of purposive socialization in economic models has been pioneered by Bisin and Verdier $(1998,2000)$. In their models, vertical socialization, along with random imitation, determines the long-term distribution of cultural traits in the population. The theory of symbolic values mainly differs from Bisin and Verdier's one in two respects. First, Bisin and Verdier assume that parents want their children to have the same cultural trait as themselves. They motivate this assumption by the possibility of "imperfect empathy" on the side of parents. This means that parents evaluate their children's actions using their (the parents') preferences. In the theory of symbolic values, parents choose the value system of their children so as to maximize the child's utility. ${ }^{2}$ Second, the objects that are transmitted from parents to children are modeled in different ways. Whereas in Bisin and Verdier's theory parents transmit a preference trait, in ours they transmit a value system. The essential property of a value system is that, taking it in conjunction with an individual's attributes, it determines the esteem enjoyed by the individual. In the theory of symbolic values, individuals have preferences over esteem and the usual list of consumption goods. The advantage of modeling socialization to a value system rather than to a preference trait is that one keeps preferences fixed, so that normative analysis based on the Pareto criterion is possible. A cost of this modeling approach is that one has to add esteem to the standard arguments of the utility function. This is also true of Bisin and Verdier's theory, which introduces the offspring's preference parameter in the parent's utility function.

\section{A model of immigrants-natives relations}

I will now apply the theory of symbolic values to study the interpersonal relations between immigrants and natives. ${ }^{3}$ Beliefs in the superiority of one's own ethnicity may have serious implications for the relations between immigrants and natives and for a coun-

\footnotetext{
${ }^{2}$ Imperfect altruism could easily be incorporated in the theory of symbolic values. Suppose that parents also care about the esteem that they receive from their children. Since the latter depends on the value that the child attaches to the parent's traits, the parent has an incentive to bias the socialization of her child in favor of her own traits.

${ }^{3}$ Bisin et al. (2008) and Della Giusta and Hashimzade (2009) offer related models of cultural assimilation of immigrants. The model in the current paper can also be interpreted as one of racial relations.
} 
try's economic performance. Immigrants constitute a sizeable share of the overall world population and often belong to the most vulnerable strata of the population. Negative stereotypes about immigrants reduce their chances in the labor market and their quality of everyday life, including life at schools and in workplaces. Natives' hostility may foster negative stereotyping by immigrants with respect to the national majority, giving rise to a mental arm race in terms of prejudices. Sometimes that race turns into episodes of violence and it often affects political outcomes. ${ }^{4}$ From an economic viewpoint, chauvinistic attitudes may be a formidable obstacle to the immigrants' integration in the domestic economy and the recognition of their talents. Natives' hostility may induce immigrants to cluster together in neighborhoods and schools, where unfavorable peer effects prevent both cognitive and noncognitive abilities to develop at their potential. In this fashion, xenophobia may generate a lasting negative impact on innovation and economic growth.

In the sequel, a formal model of immigrant-natives relations is developed that allows one to dissect the role of value formation and the interplay between symbolic values and economic outcomes. ${ }^{5}$

\subsection{Assumptions}

Consider a model economy populated by a continuum of atomistic individuals $i \in[0,1]$. Individuals have a common utility function but differ with respect to their nationality, ability, and family background. A fraction $\mu$ of the population consists of immigrants, a

\footnotetext{
${ }^{4}$ By way of an example, in Germany right-wing extremist parties could benefit from mounting xenophobia and anti-Semitism in some recent regional elections; as reported by Siedler (2008), between 1990 and 2005 the number of right-wing extremists in Germany more than doubled. Anti-immigrant feeling was a key factor in the electoral success of the National Front Party in the 2002 French election; as simulated by Roemer and Van der Straeten (2005), xenophobia substantially reduced the redistributive content of the parties' electoral platforms. Historically, feelings of superiority of own nation and race seem to have been essential ingredients for the development of fascism, colonialism and imperialism. In turn, fascist leaders used their rethoric to foster racial and ethnic divisions.

${ }^{5}$ In the Beckerian tradition, racism is an exogenous preference that implies discriminatory behavior based on race. The main insight of Becker is the role of market competition. Since racial discrimination is costly to the discriminator, free market competition drives racists out of the market. Thus, adding an evolutionary twist, thanks to markets, race-based hostility is bound to disappear. Of course, this is subject to caveats concerning the possibility of economic rents in the long run. In any case, it may take a while to arrive at the steady state and meanwhile preferences for race may persist. This raises the question of their cause. An illuminating but partial answer is provided by the approach of statistical discrimination. Groups that are readily identifiable by observers - e.g. by the color of their skin - may be known to be characterized by some average behavior. Observers use that piece of information along with other signals to forecast others' behavior. An example is when natives assign a relatively high probability to the event that an immigrant commits a crime. Hostility towards immigrants is explained as a precautionary attitude to avoid being victim of crimes. However, such attitudes often arise in absence of any compelling information about the statistical relationship between ethnicity and crime. In controlled experiments, Fershtman and Gneezy (2001) found no evidence of statistical discrimination and much evidence in support of mistaken ethnic stereotypes.
} 
fraction $1-\mu$ consists of natives; for simplicity, all immigrants are assumed to share a common nationality. Ability is summarized by the pair $(\pi, \theta)$ and family background by the pair $(\alpha, \eta)$, to be explained later. All individuals consume one homogeneous good, used as the numeraire. Each individual faces the following sequence of events: first, the individual exerts effort in order to shape his value system; this can be interpreted as a benevolent parent socializing her child. Second, the individual, given his values, decides how much effort to exert in order to achieve in economic terms. Third, Nature determines the individual achievement levels; individuals consume according to their achievements and obtain esteem and utility from interpersonal relations according to how their characteristics are valued in society.

\section{Material Outcomes}

I posit that achievement is defined in terms of the income level obtained by the individual and consider two possible outcomes, a high income level $w_{H}$ and a low income level $w_{L}$. Achieving is a random event which depends on an individual's ability or talent and his effort, given such exogenous circumstances as the quality of schooling. Denoting by $e(i)$ individual $i$ 's non-negative effort level, the probability to succeed is given by $\operatorname{Pr}\left\{w(i)=w_{H}\right\}=\pi(i)+\theta(i) e(i)$, where parameters are both non-negative. Parameter $\pi$ stands for those individual capabilities that increase achievement independently of an individual's effort; $\theta$ measures the extent to which individual achievement is responsive to individual effort. ${ }^{6}$ Effort is costly, and its cost to the individual is specialized to $e(i)^{2} / 2 \omega$, where $\omega$ is a preference parameter of the utility function.

Let $\lambda$ denote the fraction of achievers. Their wage $w_{H}(\lambda)$ is assumed to satisfy $w_{H}^{\prime}(\lambda) \leq$ 0 , while $w_{L}^{\prime}(\lambda) \geq 0$, with $w_{H}(1)>w_{L}(0)$. The first two inequalities can be seen as a reduced-form model for a labor market determination of the returns to human capital.

Value systems.

Individuals have value systems defined over two attributes: nationality $n \in\{0,1\}$ and achievement $a \in\{0,1\}$. Let $n=1$ denote domestic nationality and $a=1$ denote high income. The value attached to the trait combination an by individual $i$ is measured by a non-negative index $v_{a n}(i)$. The collection of the four $v_{a n}(i)$, one for each type, describes the value system of individual $i$; it satisfies

$$
\sum_{a=0}^{1} \sum_{n=0}^{1} v_{a n}(i)=1 .
$$

Value systems are determined by an exogenous factor that is common to all individuals with the same nationality (possibly the same for both nationalities) and by an endogenous

\footnotetext{
${ }^{6}$ Both parameters may also capture the quality of the environment, e.g. the quality of schooling.
} 
idiosyncratic factor. The common factor is the reference value system $\left\{\widehat{v}_{a n}\right\}$ for nationals and $\left\{\widetilde{v}_{a n}\right\}$ for immigrants. The reference value system mirrors public values as put forward by collective discourse. They are the outcome of a whole history of ideas and taken as exogenously given. By way of an example, public values that stress the fundamentally equal worth of all individuals, independently of their traits, may be captured by $\widehat{v}_{a n}=1 / 4$ for all $a$ and $n$. Public values that stress the superiority of own country of origin may instead give rise to $\widehat{v}_{a 1}>\widehat{v}_{a 0}$ and $\widetilde{v}_{a 0}>\widetilde{v}_{a 1}$; public values that stress the special worth of individual accomplishments may induce $\widehat{v}_{1 n}>\widehat{v}_{0 n}$ and $\widetilde{v}_{1 n}>\widetilde{v}_{0 n}$.

The idiosyncratic factor captures how an individual is socialized. I concentrate on vertical socialization by benevolent parents, thus abstracting from horizontal and oblique socialization. If parents do not exert effort, individuals are assumed to endorse the reference value system of their nationality. By exerting efforts, parents can shift their child's values away from the reference value system. This captures the malleability of character during childhood and early adolescence that has been identified by research on human development. $^{7}$

Parents who invest in their children's values may influence the relative value that their children attach to achievement, which is given by $\sum_{n=0}^{1} v_{1 n}(i)-\sum_{n=0}^{1} v_{0 n}(i)$. At the same time, they may influence the relative value that their children attach to nationality, $\sum_{a=0}^{1} v_{a 1}(i)-\sum_{a=0}^{1} v_{a 0}(i)$. Parents' influence depends on the resources that they invest in socialization. Let $\delta_{a}(i)$ and $\delta_{n}(i)$ respectively denote a parent's investment in achievementorientation and in nationalism; the resulting value system for a domestic citizen is given by:

$$
\begin{aligned}
& v_{11}(i)=\max \left\{\min \left\{\widehat{v}_{11}+\delta_{a}(i)+\delta_{n}(i), 1\right\}, 0\right\} \\
& v_{01}(i)=\max \left\{\min \left\{\widehat{v}_{01}-\delta_{a}(i)+\delta_{n}(i), 1\right\}, 0\right\} \\
& v_{10}(i)=\max \left\{\min \left\{\widehat{v}_{10}+\delta_{a}(i)-\delta_{n}(i), 1\right\}, 0\right\} \\
& v_{00}(i)=\max \left\{\min \left\{\widehat{v}_{00}-\delta_{a}(i)-\delta_{n}(i), 1\right\}, 0\right\} .
\end{aligned}
$$

Analogous expressions hold for immigrants after substituting $\widehat{v}_{a n}$ with the corresponding

\footnotetext{
${ }^{7}$ See e.g. Cunha and Heckman (2009) for an excellent survey.
} 
$\widetilde{v}_{a n} \cdot{ }^{8}$ Without significant loss of generality, I assume that parameters are such that parents choose internal values, i.e. $v_{a n}(i) \in(0,1)$ for all $a, n$ and $i$.

Instilling values is assumed to be costly for parents. First, there is a cost caused by the overall amount of socialization effort exerted by parents; this cost increases with $\left|\delta_{a}(i)\right|+$ $\left|\delta_{n}(i)\right|$. Second, parents incur a specific cost for manipulating the value attached to each trait, achievement and nationality. Those costs depend on a parent's skill in transmitting values. Parents whose own value system attaches a large value to achievement must spend less effort in order to obtain a given increase in her children's valuation of achievement as compared to parents who attach little value to achievement. Similarly, nationalistic parents have a comparative advantage in transmitting an attachment to own nation. For simplicity, I assume that total costs incurred by an individual's parent to socialize her child are given by

$$
\frac{\left(\left|\delta_{a}(i)\right|+\left|\delta_{n}(i)\right|\right)^{2}}{2 \sigma}+\frac{\delta_{a}(i)^{2}}{2 \alpha}+\frac{\delta_{n}(i)^{2}}{2 \eta} .
$$

Parameters $\alpha$ and $\eta$ may be thougth of as capturing both the values of the parents and the intrinsic strength of the national value system: the weaker parents' valuation of a given trait and the more convincing the reference value system of their group, the larger are the costs to inculcate different values, and the small are $\alpha$ and $\eta$.

\section{Utility function.}

Individuals care about consumption and esteem, in addition to the effort costs incurred when socializing their children and acquiring human capital. Preferences are additively separable and represented by the utility function

$$
U(i)=c(i)+\beta \operatorname{self} v(i)+\gamma \operatorname{socv}(i)-\left[\frac{\left(\left|\delta_{a}(i)\right|+\left|\delta_{n}(i)\right|\right)^{2}}{2 \sigma}+\frac{\delta_{a}(i)^{2}}{2 \alpha}+\frac{\delta_{n}(i)^{2}}{2 \eta}+\frac{e(i)^{2}}{2 \omega}\right] .
$$

The first term on the r.h.s. captures utility from consumption, which is given by the individual's wage. The second one captures utility from self-esteem. An individual's selfesteem is the esteem in which he holds his type: if an individual $i$ is the type an, his self-esteem is given by $v_{a n}(i)$. The third term of the utility function captures utility from social interactions. Independently of their nationality, adult individuals are randomly matched into pairs. ${ }^{9}$ At each encounter they exchange courtesy or hostility according to their traits and values. Courtesy and hostility are relational goods that are not exchanged

\footnotetext{
${ }^{8}$ Notice that an immigrant's parent who wants to increase the value attached by her child to own nationality chooses $\delta_{n}<0$.

${ }^{9}$ An alternative assumption is social segregation, where individuals have a higher probability to meet somebody of the same nationality. This may be a better assumption if one is to analyze racial relations in US ghettos. That assumption generates the possibility of diverging conformist effects in values and behavior across races.
} 
through markets but through social interactions. I refer to them as the social esteem enjoined by individuals. The esteem that an individual receives from a social contact depends on the value attached by his social contact on the individual's type. I assume that nationality is perfectly observed by social contacts, while achievement is observed with probability $1-\rho$. The expected social esteem received by a native with achievement level $a$ is therefore given by

$$
\operatorname{socv}(i)=(1-\rho) \int_{0}^{1} v_{a 1}(j) d j+\rho\left[\widehat{a} \int_{0}^{1} v_{11}(j) d j+(1-\widehat{a}) \int_{0}^{1} v_{01}(j) d j\right],
$$

where $\widehat{a}$ is the fraction of achievers in the native population. A symmetric definition of socv $(i)$ applies for migrants.

The preference parameters $\beta$ and $\gamma$ are strictly positive and capture the strength of value concerns.

\section{Equilibrium.}

An equilibrium is a situation in which each agent chooses his effort levels to shape his values and to build human capital so as to maximize his expected utility, taking the choices of all other agents as given. To shorten the exposition, I only consider parameter constellations that give rise to equilibria that are interior with respect to the probability to achieve, i.e. such that $\pi+\theta e \in(0,1)$.

\subsection{Individual optimization}

At the family level, both the wage structure and levels of social esteem are taken as exogenouos. A native family maximizes

$(\pi+\theta e)\left[w_{H}+\beta\left(\widehat{v}_{11}+\delta_{a}+\delta_{n}\right)+\gamma \operatorname{socv}_{11}\right]+(1-\pi-\theta e)\left[w_{L}+\beta\left(\widehat{v}_{01}-\delta_{a}+\delta_{n}\right)+\gamma \operatorname{socv}_{01}\right]-C\left(\delta_{a}, \delta_{n}, e\right)$,

where

$$
C\left(\delta_{a}, \delta_{n}, e\right)=\frac{\left(\left|\delta_{a}\right|+\left|\delta_{n}\right|\right)^{2}}{2 \sigma}+\frac{\delta_{a}{ }^{2}}{2 \alpha}+\frac{\delta_{n}{ }^{2}}{2 \eta}+\frac{e^{2}}{2 \omega}
$$

is a shorthand for the costs incurred by the agent as a function of his three control variables. The immigrants' decision problem is similar and will not be explicitly presented.

As a first step, it is instructive to discuss the determination of the child's achievement level. When the child selects his effort, his value system has already crystallized, inducing reduced-form preferences for effort summarized by the objective function

$$
(\pi+\theta e)\left(w_{H}+\beta v_{11}+\gamma s o c v_{11}\right)+(1-\pi-\theta e)\left(w_{L}+\beta v_{01}+\gamma s o c v_{01}\right)-\frac{e^{2}}{2 \omega} .
$$


The first-order condition for an interior maximum entails

$$
e^{*}=\omega \theta\left[\left(w_{H}-w_{L}\right)+\beta\left(v_{11}-v_{01}\right)+\gamma\left(\operatorname{socv}_{11}-\operatorname{socv}_{01}\right)\right] .
$$

Thus, an individual's expected achievement $\pi+\theta e^{*}$ is driven by four factors: his ability, as proxied by $\pi$ and $\theta$, his character, as proxied by $v_{11}-v_{01}$, pecuniary incentives, $w_{H}-w_{L}$, and social incentives, $\operatorname{socv}_{11}-\operatorname{socv}_{01}$. As shown by (5), values transmitted to the individual by society and his parents generate an incentive effect: the individual's effort is strictly increasing with $v_{11}-v_{01}=\widehat{v}_{11}-\widehat{v}_{01}+2 \delta_{a}$. The intuition is simple: the larger the value attached to achievement, the larger is the self-esteem obtained from achieving relative to the self-esteem in case of failure, and the stronger is the incentive for the individual to exert effort.

When parents socialize their children, they anticipate the incentive effect of value transmission. The result of their maximization exercise is described in the following ${ }^{10}$

Proposition 1 A unique optimal strategy always exists and has $\delta_{n}^{*}>0$ in case of natives and $\delta_{n}^{*}<0$ in case of immigrants. Depending on parameter values, one of the following cases occur at the optimum: 1) $\delta_{a}^{*}<0, e^{*}=0$;2) $\delta_{a}^{*}<0, e^{*}>0$; 3) $\delta_{a}^{*}=0, e^{*}>0$; 4) $\delta_{a}^{*}>0, e^{*}>0$.

Parents have an incentive to invest in nationalism because it has a positive influence on the child's self-esteem for sure and a small investment causes negligible costs. Instead, parents do not necessarily invest in the achievement-orientation of their children. The welfare impact of investing in achievement orientation can be decomposed into a mechanical and a behavioral effect. The mechanical effect is the expected change in self-esteem caused by attaching more value to achievement. Its expected return is positive if and only if the probability for the child to be an achiever (given by $\pi+\theta e$ ) is larger than the probability to be a loser (given by $1-\pi-\theta e$ ). The behavioral effect is the change in the marginal return to effort. Increasing the achievement-orientation of the child generates an incentive to exert more effort because the achievement orientation increases the loss of self-esteem in case of failure. If the probability to achieve is low, the mechanical effect may dominate and the parent may decide to invest to decrease the achievement orientation of her child $\left(\delta_{a}^{*}<0\right)$. If the probability is high, the mechanical effect and the behavioral effect may reinforce each other and the parent may choose to enhance the achievement orientation of her child $\left(\delta_{a}^{*}>0\right)$.

\footnotetext{
${ }^{10}$ Proofs of all propositions appear in the Appendix. In order for the maximization problems to be well-behaved, parameters must satisfy$$
\alpha+\eta+\sigma>4 \alpha \beta^{2} \theta^{2} \omega(\eta+\sigma),
$$

which I assume to be the case throught the paper.
} 


\subsection{General equilibrium}

At the general-equilibrium level, the income levels of achievers and losers and the social esteem of each type are endogenous. The wage determination follows the usual logic of scarcity: the wage differential is given by

$$
\Delta w=w_{H}((1-\mu) \widehat{a}+\mu \widetilde{a})-w_{L}((1-\mu) \widehat{a}+\mu \widetilde{a}),
$$

which is decreasing in the fraction of achievers in the two groups, $\widehat{a}$ and $\widetilde{a}$.

The difference in social esteem between achievers and losers reads

$$
\Delta \widehat{\operatorname{socv}}=(1-\rho)\left[(1-\mu)\left(\widehat{v}_{11}-\widehat{v}_{01}+2 \widehat{\delta}_{a}\right)+\mu\left(\widetilde{v}_{11}-\widetilde{v}_{01}+2 \widetilde{\delta}_{a}\right)\right]
$$

for natives and

$$
\Delta \widetilde{\operatorname{socv}}=(1-\rho)\left[(1-\mu)\left(\widehat{v}_{10}-\widehat{v}_{00}+2 \widehat{\delta}_{a}\right)+\mu\left(\widetilde{v}_{10}-\widetilde{v}_{00}+2 \widetilde{\delta}_{a}\right)\right]
$$

for immigrants, where $\widehat{\delta}_{a}$ and $\widetilde{\delta}_{a}$ are the average investments in achievement orientation in the two groups. Those average investments increase the social esteem of the achievers and decrease the social esteem of the losers, and hence raise the esteem differential.

The following fact can be established:

Proposition 2 A general equilibrium always exists. Multiple equilibria are possible if $\rho<1$ and $\gamma$ is sufficiently large.

Multiple equilibria are interesting as they point out the possibility of a drastic effect from improved schooling. In case of multiple stable equilibria, a low-achievementorientation, low-effort equilibrium coexists with a high-achievement-orientation, higheffort equilibrium. Then, a small schooling reform that marginally increases children's abilities $(\pi, \theta)$ may eliminate an equilibrium with low achievement orientation, and therefore low social esteem to achievers, and make the economy jump to an achievementoriented one, where achievers obtain a high level of social esteem. In this case, output grows and the skill wage differential $w_{H}-w_{L}$ decreases because of the increase in the fraction of achievers.

The conditions for equilibrium multiplicity can be explained as follows. Parents' socialization efforts generate an externality because their children's values determine how others fare in social interactions. Multiplicity arises if those externalities induce other parents to change their socialization efforts. An increase of achievement orientation for some children increases the social esteem received by achievers as compared to losers; this 
strengthens the incentive for other children to exert effort, hence their probability to succeed increases. As a consequence, their parents have an incentive to raise the achievement orientation of their children, i.e. a bandwagon effect of increasing achievement orientation sets in. In order for this cumulative causation to occur, an increase of achievement orientation must effectively increase the esteem received by achievers relative to that received by losers, socv $_{1 n}-\operatorname{socv}_{0 n}$. This is only possible if achievement is observable $(\rho<1)$. If achievement is private information, all natives get the same social esteem, independently of their achievement, all immigrants get the same social esteem, independently of their achievement, and social esteem has no behavioral effect.

In order for that cumulative causation to generate multiple equilibria, utility must respond strongly enough to changes in social esteem. If a low-achievement-orientation, low-effort economy is an equilibrium, a high-achievement-orientation, high-effort economy can also be an equilibrium only if the gain of social esteem of achievers in the latter case compensates in utility terms the associated higher effort cost and lower income gain. This requires $\gamma$ to be sufficiently large. ${ }^{11}$

\subsection{Predictions for nationalism}

While natives and immigrants have similar incentives to shape values about achievement, they have diametrically opposed incentives with respect to nationalism. Indeed, two individuals that only differ with respect to their nationality optimally choose opposite levels of $\delta_{n}$; those magnitudes determine the diffidence that they experience when they interact. Hence, investments in nationalism may be seen as proxies for interethnic conflict or inversely related to the quality of social interactions between natives and immigrants. ${ }^{12}$

In the current model, nationalism can be predicted by ability. The following result is stated for natives and an equivalent one holds true for immigrants.

Proposition 3 Increasing $\pi$ gradually moves the optimal strategy from configuration 1 to 2 to 3 to 4 as of Proposition 1. The correlation between natives' nationalism and ability is $\frac{\partial \delta_{n}^{*}}{\partial \pi}>0$ in configurations 1 and $2, \frac{\partial \delta_{n}^{*}}{\partial \pi}=0$ in configuration 3 , and $\frac{\partial \delta_{n}^{*}}{\partial \pi}<0$ in configuration 4 .

In configurations 1 and 2 the ability parameter $\pi$ is very low and parents invest to decrease the value attached to achievement $\left(\delta_{a}^{*}<0\right)$ in order to raise the child's future

\footnotetext{
${ }^{11}$ A similar logic explains the existence of ghetto cultures, where social esteem is obtained in some groups not from achieving in terms of personal income but from achieving in other dimensions, e.g. sexual prowess; see Anderson (1999).

${ }^{12}$ This is consistent with a line of thougth that goes back to Voltaire and the Frankfurt sociological school and that purports that national pride implies ethnic prejudice. For a recent, more differentiated, assessment, see de Figueiredo and Elkins (2003).
} 
self-esteem. In those parameter regions, when $\pi$ grows, parents become less sure that the child will be a loser. Then, an increase of $\pi$ leads them to make $\delta_{a}^{*}$ less negative, i.e. they come closer to their group's reference values: parents' socialization efforts as expressed by $\left|\delta_{a}^{*}\right|$ decrease. As a consequence, the marginal costs of investing in nationalism become lower. This leads parents to increase $\delta_{n}^{*}$.

A further increase of $\pi$ moves the optimal strategy into configuration 3. This region is characterized by a corner solution with respect to achievement orientation, i.e. $\delta_{a}^{*}=0$ : the agent endorses the valuation of achievement given by the reference value system of his nationality. This is the parameter region where nationalism reaches its peak since parents can devote their entire socialization efforts to it: no effort is devoted to affect the achievement orientation of children. This occurs because the ability of the child is perceived to be insufficient to make achievement a likely outcome.

If $\pi$ crosses some threshold, parents invest in achievement values $\left(\delta_{a}^{*}>0\right)$ and configuration 4 occurs. In this region, the complementarity between socialization and child's effort sets in. An increase in $\pi$ leads parents to invest more value in achievement, which increases effort, which increases the probability to succeed, which makes investing in achievement even more appealing. The ensuing increase in the marginal costs of socialization leads parents to decrease their investment in nationalism. An increase in child's ability makes therefore parents subtitute nationalism with achievement orientation.

The comparative statics of $\theta$ can be explained along similar lines. In configuration $1, e^{*}=0$ so that $\theta$ does not matter. In configurations 2,3 and 4 the effect from $\theta$ is qualitatively identical to the one from $\pi$.

In the most general case, ability entertains a hump-shaped relationship with nationalistic attitudes. At very low levels of ability - such that $e^{*}=0$ and/or $\delta_{a}^{*} \leq 0$ - nationalism is increasing with ability. At intermediate levels, nationalism peaks and small changes in ability have no effect on it. At higher levels of ability, nationalism continuously declines with ability.

To the extent that $\pi$ and $\theta$ do not only mirror genetic traits but also capture the quality of schooling, Proposition 3 generates a novel insight into education policy. Schooling may have repercussions beyond the skill level of the population: it may also affect how parents socialize their children and how those children interact with immigrants. More efficient schooling may increase the level of human capital of the next generation because it strengthens the incentive for parents to tilt their children's character away from complacency and towards conscientiosness and perseverance. In this way, better schooling may have an impact on nationalism and xenophobia, reducing them if school quality is such that configuration 4 of Proposition 1 applies. 


\section{Corroborating evidence}

The theoretical model suggests that ability is an explanatory factor of nationalistic attitude. According to Proposition 3, there is an inverted-U relationship between the two variables: there can exist ability levels that are so low that nationalism increases with ability but as soon as some intermediate ability level is reached, nationalism is predicted to decrease with ability. In what follows, I examine that prediction in three data sets: the German DJI Youth Survey, the "National Identity 2003" module of the International Social Survey Programme (ISSP), and the World Value Survey (WVS). In those three surveys, an individual's ability can be measured by the individual's educational attainment. An individual's nationalism can be recovered from the answer given to the following question: "How proud are you of being [COUNTRY NATIONALITY]?". Respondents choose from "Very proud", "Somewhat proud", Not very proud", "Not proud at all". The answer to that question is arguably a reliable indicator of an individual's self-esteem derived from own nationality.

\subsection{German youth}

The German DJI Youth Survey is a repeated cross-sectional survey which was carried out in 1992, 1997 and 2003. About 20,000 young adults aged 16-29 were interviewed and the survey was designed to be representative of the total German population in that age range. Focusing on young people, it is especially suitable for testing the proposed theoretical model since reported values are not yet affected by the individuals' experience of adult life. Individual ability, measured by a respondent's highest school degree, is available in three categories: "No degree or secondary general school degree"; "Intermediate school degree"; "High school degree". Some respondents are still in school; since their educational

attainment is not necessarily their definitive one, they are omitted from the analysis. I also omit respondents who have not the German nationality.

The estimated effect of ability on nationalism is displayed in Table 1 . The first two columns report results from a binary logit estimation; nationalism is coded as 1 if the respondent is very proud of being German and 0 otherwise. The remaining columns report estimations from an ordered logit model.

TABLE 1: Binary and ordered logit regressions predicting nationalism in DJI data. 


\begin{tabular}{lllll}
\hline & $(1)$ & $(2)$ & $\left(1^{\prime}\right)$ & $\left(2^{\prime}\right)$ \\
\hline Age & $-0.216^{*}$ & $-0.258^{*}$ & $-0.119^{*}$ & -0.097 \\
& $(0.086)$ & $(0.125)$ & $(0.055)$ & $(0.084)$ \\
Age squared & $0.004^{*}$ & 0.005 & 0.002 & 0.002 \\
& $(0.002)$ & $(0.003)$ & $(0.001)$ & $(0.002)$ \\
Female & $-0.470^{* * *}$ & $-0.507^{* * *}$ & $-0.419^{* * *}$ & $-0.437^{* * *}$ \\
& $(0.052)$ & $(0.066)$ & $(0.031)$ & $(0.041)$ \\
Low education & $0.359^{* * *}$ & $0.330^{* * *}$ & $0.200^{* * *}$ & $0.238^{* * *}$ \\
& $(0.057)$ & $(0.067)$ & $(0.040)$ & $(0.046)$ \\
High education & $-0.730^{* * *}$ & $-0.520^{* * *}$ & $-0.734^{* * *}$ & $-0.560^{* * *}$ \\
& $(0.068)$ & $(0.093)$ & $(0.036)$ & $(0.050)$ \\
Wave 1997 & $0.120^{*}$ & 0.108 & $0.125^{* * *}$ & $0.102^{*}$ \\
& $(0.061)$ & $(0.073)$ & $(0.037)$ & $(0.047)$ \\
Wave 2003 & 0.010 & -0.041 & $0.246^{* * *}$ & $0.210^{* * *}$ \\
& $(0.063)$ & $(0.077)$ & $(0.038)$ & $(0.048)$ \\
Married & & $0.347^{* * *}$ & & $0.337^{* * *}$ \\
Widowed & & $(0.080)$ & & $(0.051)$ \\
& & & & -0.620 \\
Divorced & & & & $(1.084)$ \\
& & -0.107 & & $-0.270^{*}$ \\
Seperated & & $(0.228)$ & & $(0.134)$ \\
Primary income source: & & 0.155 & & -0.087 \\
Part-time work & & $(0.332)$ & & $(0.203)$ \\
Not working & & -0.058 & & $-0.255^{* * *}$ \\
& & $(0.129)$ & & $(0.075)$ \\
Unemployment Benefits & & -0.028 & & $-0.169^{* *}$ \\
& & $0.100)$ & & $(0.062)$ \\
Bayesian Information Criterion & 10,944 & $0.283^{* * *}$ & & -0.079 \\
Observations & 14,583 & $9,3681)$ & 37,060 & 23,261 \\
\hline
\end{tabular}

The results show that educational attainment has a strongly significant impact on the degree of nationalism of the German youth. Individuals with low education are more nationalistic than individuals with intermediate education while individuals with high education are less nationalistic than individuals with intermediate education. The implied negative causal effect of ability on nationalism is consistent with the comparative statics of the model where optimal strategies are based on parameter constellations that lead to configuration 4, i.e. ability levels are relatively high.

Is nationalism associated with negative attitudes towards immigrants? Table 2 shows that in the DJI Youth Survey this is clearly the case. Nationalism is strongly correlated with a number of proxies of xenophobia derived from various survey questions. All 
reported correlation coefficients are statistically significant at the $1 \%$ level.

\section{TABLE 2: Correlation coefficients for nationalism and various measures of xenophobia.}

\begin{tabular}{|l|c|}
\hline Question & Correlation with nationalism \\
\hline $\begin{array}{l}\text { If jobs become rare, foreigners should be } \\
\text { sent to their home countries }\end{array}$ & 0.33 \\
\hline $\begin{array}{l}\text { Foreigners should have the same rights } \\
\text { as Germans in all domains }\end{array}$ & -0.23 \\
\hline $\begin{array}{l}\text { I support the presence of foreigners } \\
\text { because they enrich own cultural life }\end{array}$ & -0.28 \\
\hline $\begin{array}{l}\text { It would be best if all foreigners leave } \\
\text { Germany }\end{array}$ & 0.30 \\
\hline $\begin{array}{l}\text { It is acceptable: Using violent means to } \\
\text { make it clear to asylum-seekers that they } \\
\text { should return to their home country }\end{array}$ & 0.26 \\
\hline
\end{tabular}

This evidence is in line with recent findings by Card et al. (2009) on the determinants of attitudes towards immigration in a sample of twenty-two European countries. They find that "compositional amenities" - associated with the non-economic consequences of immigration - are substantially more important in explaining attitudes than concerns over the impacts of immigration on wages and taxes. Moreover, those amenity effects are especially strong in case of attitudes of less-educated individuals.

\subsection{ISSP}

The "National Identity 2003" module of the International Social Survey Programme (ISSP) covers most OECD countries; it samples about 45,000 adult individuals. An advantage of this data source as compared to the DJI Survey is that educational attainment is more finely coded according to the following six categories: "No education"; "Primary education", "Some secundary education", Secundary education", "Above secundary education", "Tertiary education". Regression results are exhibited in Table 3. Again, the first two columns report results from a binary logit estimation and the two other columns report estimations from an ordered logit model. All regressions include unreported country dummies; standard errors are adjusted for clustering by country of the respondent.

TABLE 3: Binary and ordered logit regressions predicting nationalism in ISSP data. 


\begin{tabular}{|c|c|c|c|c|}
\hline & (1) & $(2)$ & $\left(1^{\prime}\right)$ & $\left(2^{\prime}\right)$ \\
\hline \multirow[t]{2}{*}{ No education } & 0.137 & 0.137 & 0.110 & 0.117 \\
\hline & $(0.153)$ & $(0.150)$ & $(0.143)$ & $(0.143)$ \\
\hline \multirow[t]{2}{*}{ Primary education } & $0.161^{* * *}$ & $0.158^{* * *}$ & $0.147^{* * *}$ & $0.145^{* * *}$ \\
\hline & $(0.040)$ & $(0.040)$ & $(0.039)$ & $(0.038)$ \\
\hline \multirow[t]{2}{*}{ Secundary education } & $-0.179^{* * *}$ & $-0.175^{* * *}$ & $-0.171^{* * *}$ & $-0.171^{* * *}$ \\
\hline & $(0.045)$ & $(0.044)$ & $(0.034)$ & $(0.034)$ \\
\hline \multirow[t]{2}{*}{ Above secundary education } & $-0.271^{* * *}$ & $-0.261^{* * *}$ & $-0.249^{* * *}$ & $-0.241^{* * *}$ \\
\hline & $(0.052)$ & $(0.052)$ & $(0.047)$ & $(0.047)$ \\
\hline \multirow[t]{2}{*}{ Tertiary education } & $-0.590^{* * *}$ & $-0.581^{* * *}$ & $-0.524^{* * *}$ & $-0.524^{* * *}$ \\
\hline & $(0.070)$ & $(0.071)$ & $(0.061)$ & $(0.062)$ \\
\hline \multirow[t]{2}{*}{ Age } & 0.012 & 0.008 & 0.008 & 0.002 \\
\hline & $(0.007)$ & $(0.008)$ & $(0.006)$ & $(0.007)$ \\
\hline \multirow[t]{2}{*}{ Age squared } & 0.000 & 0.000 & 0.000 & 0.000 \\
\hline & $(0.000)$ & $(0.000)$ & $(0.000)$ & $(0.000)$ \\
\hline \multirow[t]{2}{*}{ Female } & -0.002 & 0.012 & 0.026 & 0.044 \\
\hline & $(0.040)$ & $(0.038)$ & $(0.036)$ & $(0.033)$ \\
\hline \multicolumn{5}{|l|}{ Legal status: } \\
\hline \multirow[t]{2}{*}{ Married } & & $0.114^{*}$ & & $0.134^{* * *}$ \\
\hline & & $(0.047)$ & & $(0.040)$ \\
\hline \multirow[t]{2}{*}{ Widowed } & & 0.057 & & 0.070 \\
\hline & & $(0.059)$ & & $(0.056)$ \\
\hline \multirow[t]{2}{*}{ Divorced } & & 0.025 & & -0.007 \\
\hline & & $(0.049)$ & & $(0.042)$ \\
\hline \multirow[t]{2}{*}{ Seperated } & & -0.002 & & -0.020 \\
\hline & & $(0.093)$ & & $(0.101)$ \\
\hline \multicolumn{5}{|l|}{ Primary income source: } \\
\hline \multirow[t]{2}{*}{ Part time work } & & $-0.112^{* *}$ & & $-0.138 * * *$ \\
\hline & & $(0.042)$ & & $(0.041)$ \\
\hline \multirow[t]{2}{*}{ Housewife } & & -0.023 & & -0.030 \\
\hline & & $(0.055)$ & & $(0.057)$ \\
\hline \multirow[t]{2}{*}{ Unemployed } & & 0.030 & & -0.039 \\
\hline & & $(0.071)$ & & $(0.078)$ \\
\hline \multirow[t]{2}{*}{ Student } & & -0.008 & & -0.046 \\
\hline & & $(0.062)$ & & $(0.062)$ \\
\hline \multirow[t]{2}{*}{ Retired } & & $0.110^{*}$ & & 0.084 \\
\hline & & $(0.051)$ & & $(0.047)$ \\
\hline \multirow[t]{2}{*}{ Disabled } & & 0.219 & & 0.150 \\
\hline & & $(0.125)$ & & $(0.117)$ \\
\hline Other & & 0.068 & & 0.050 \\
\hline Bayesian Information Criterion & 49,663 & 49,198 & 76,689 & 75,890 \\
\hline Observations & 41,470 & 41,033 & 41,470 & 41,033 \\
\hline
\end{tabular}

Note: All regressions include country dummies.

The omitted education category is "Some secundary education". For higher educa- 
tional attainments, the results show again a negative relationship between education and nationalism. That negative relationship extends to those with only "Primary education", who are found to be more nationalistic than those with "Some secundary education". However, at even lower attainments ("No education") there is no statistically significant effect of education on nationalism, i.e. the nationalism of individuals with no education seems to be closer to that of individuals with some secundary education than to that of individuals with only primary education. ${ }^{13}$

\subsection{WVS}

The third data souce is the World Value Survey in its waves 1989-1993, 1994-1999, 19992004 and 2005. The distinctive advantage of this source is that it includes many developing countries where educational attainment is relatively low; the sample has more than 250,000 observations.

TABLE 4: Binary and ordered logit regressions predicting nationalism in WVS data.

\footnotetext{
${ }^{13}$ In this data source there is a survey question directly related to the relative value assigned to the respondent's country. Individuals were asked whether they agree with the following statement: "Generally speaking, [COUNTRY] is a better country than most other countries". Answers are significantly correlated with the nationalism proxy used in the regressions, with a correlation coefficient of 0.33 .
} 


\begin{tabular}{|c|c|c|c|c|}
\hline & $(1)$ & $(2)$ & $\left(1^{\prime}\right)$ & $\left(2^{\prime}\right)$ \\
\hline \multirow[t]{2}{*}{ No education } & -0.054 & -0.044 & -0.061 & -0.048 \\
\hline & $(0.06)$ & $(0.06)$ & $(0.06)$ & $(0.07)$ \\
\hline \multirow[t]{2}{*}{ Primary education } & $0.096^{* *}$ & $0.089^{* *}$ & $0.099^{* *}$ & $0.095^{* *}$ \\
\hline & $(0.03)$ & $(0.03)$ & $(0.03)$ & $(0.03)$ \\
\hline \multirow[t]{2}{*}{ Secundary education } & $-0.118^{* * *}$ & $-0.125^{* * *}$ & $-0.122^{* * *}$ & $-0.127^{* * *}$ \\
\hline & $(0.02)$ & $(0.02)$ & $(0.02)$ & $(0.02)$ \\
\hline \multirow[t]{2}{*}{ Tertiary education } & $-0.263^{* * *}$ & $-0.254^{* * *}$ & $-0.261^{* * *}$ & $-0.259^{* * *}$ \\
\hline & $(0.05)$ & $(0.05)$ & $(0.04)$ & $(0.04)$ \\
\hline \multirow[t]{2}{*}{ Female } & $-0.048^{*}$ & $-0.058 * *$ & -0.018 & -0.025 \\
\hline & $(0.02)$ & $(0.02)$ & $(0.02)$ & $(0.02)$ \\
\hline \multirow[t]{2}{*}{ Age } & -0.004 & $-0.008^{*}$ & -0.004 & $-0.009 * *$ \\
\hline & $(0.00)$ & $(0.00)$ & $(0.00)$ & $(0.00)$ \\
\hline \multirow[t]{2}{*}{ Age squared } & $0.000^{* * *}$ & $0.000^{* * *}$ & $0.000^{* * *}$ & $0.000 * * *$ \\
\hline & $(0.00)$ & $(0.00)$ & $(0.00)$ & $(0.00)$ \\
\hline \multirow[t]{2}{*}{ Married } & & $0.108^{* * *}$ & & $0.127^{* * *}$ \\
\hline & & $(0.03)$ & & $(0.03)$ \\
\hline \multirow[t]{2}{*}{ Divorced } & & $-0.091^{*}$ & & $-0.117^{* *}$ \\
\hline & & $(0.04)$ & & $(0.04)$ \\
\hline \multirow[t]{2}{*}{ Widowed } & & 0.039 & & 0.054 \\
\hline & & $(0.04)$ & & $(0.04)$ \\
\hline \multicolumn{5}{|l|}{ Primary income source: } \\
\hline \multirow[t]{2}{*}{ Part-time work } & & $-0.074^{*}$ & & $-0.082^{* *}$ \\
\hline & & $(0.03)$ & & $(0.03)$ \\
\hline \multirow[t]{2}{*}{ Self-employment } & & $-0.121^{* * *}$ & & $-0.139^{* * *}$ \\
\hline & & $(0.03)$ & & $(0.03)$ \\
\hline \multirow[t]{2}{*}{ Pension } & & $0.112^{* *}$ & & $0.086^{*}$ \\
\hline & & $(0.04)$ & & $(0.04)$ \\
\hline \multirow[t]{2}{*}{ Housewife } & & 0.039 & & 0.026 \\
\hline & & $(0.03)$ & & $(0.03)$ \\
\hline \multirow[t]{2}{*}{ Student } & & -0.020 & & -0.025 \\
\hline & & $(0.03)$ & & $(0.03)$ \\
\hline \multirow[t]{2}{*}{ Unemployment benefits } & & -0.082 & & $-0.124^{* *}$ \\
\hline & & $(0.04)$ & & $(0.04)$ \\
\hline \multirow[t]{2}{*}{ Other } & & -0.043 & & -0.058 \\
\hline & & $(0.05)$ & & $(0.04)$ \\
\hline Bayesian Information Criterion & 288,413 & 273,944 & 437,616 & 418,263 \\
\hline Observations & 249,416 & 236,912 & 249,416 & 236,912 \\
\hline
\end{tabular}

Note: All regressions include country and wave dummies.

Table 4 confirms the results from the above analyses. The declining part of the humpshaped relationship between ability and nationalism put forward by the theoretical model is clearly detectable in the data, while there is some weak evidence in support of the increasing part of that relationship. 
The last wave of the WVS includes information about the nationality of the respondents' parents. According to the theoretical approach proposed in this paper, foreign parents of naturalized individuals are predicted to induce less nationalism because they are unlikely to endorse it in first place - their $\eta$ is lower, i.e. it is more costly for them to instill nationalism. Furthermore, socialization may have taken place behind a veil of ignorance, i.e. before migration; this may also imply a lower degree of nationalism for children of foreign parents. Table 5 presents regression results when parent's immigrant status is controlled for. Consistently with expectations, immigrated parents seem to lower their children's degree of nationalism. Moreover, individuals with no education are found to be significantly less nationalistic than individuals with some secundary education. This

lends some empirical support to the increasing part of the relationship between ability and nationalism put forward by the theoretical model.

TABLE 5: Binary and ordered logit regressions predicting nationalism in WVS data, wave 2005. 


\begin{tabular}{|c|c|c|c|c|}
\hline & $(1)$ & $(2)$ & $\left(1^{\prime}\right)$ & $\left(2^{\prime}\right)$ \\
\hline No education & $\begin{array}{l}-0.204^{* * *} \\
(0.04)\end{array}$ & $\begin{array}{l}-0.181^{* * *} \\
(0.05)\end{array}$ & $\begin{array}{l}-0.227^{* * *} \\
(0.04)\end{array}$ & $\begin{array}{l}-0.204^{* * *} \\
(0.05)\end{array}$ \\
\hline Primary education & $\begin{array}{l}0.063^{*} \\
(0.03)\end{array}$ & $\begin{array}{l}0.074^{*} \\
(0.03)\end{array}$ & $\begin{array}{l}0.067^{*} \\
(0.03)\end{array}$ & $\begin{array}{l}0.082^{* *} \\
(0.03)\end{array}$ \\
\hline Secundary education & $\begin{array}{l}-0.086^{* *} \\
(0.03)\end{array}$ & $\begin{array}{l}-0.082^{* *} \\
(0.03)\end{array}$ & $\begin{array}{l}-0.078^{* *} \\
(0.03)\end{array}$ & $\begin{array}{l}-0.075^{* *} \\
(0.03)\end{array}$ \\
\hline Tertiary education & $\begin{array}{l}-0.220^{* * *} \\
(0.03)\end{array}$ & $\begin{array}{l}-0.218^{* * *} \\
(0.03)\end{array}$ & $\begin{array}{l}-0.226^{* * *} \\
(0.03)\end{array}$ & $\begin{array}{l}-0.227^{* * * *} \\
(0.03)\end{array}$ \\
\hline Female & $\begin{array}{l}-0.086^{* * *} \\
(0.02)\end{array}$ & $\begin{array}{l}-0.082^{* * *} \\
(0.02)\end{array}$ & $\begin{array}{l}-0.059^{* *} \\
(0.02)\end{array}$ & $\begin{array}{l}-0.054^{* *} \\
(0.02)\end{array}$ \\
\hline Age & $\begin{array}{l}-0.003 \\
(0.00)\end{array}$ & $\begin{array}{l}-0.003 \\
(0.00)\end{array}$ & $\begin{array}{l}-0.004 \\
(0.00)\end{array}$ & $\begin{array}{l}-0.006 \\
(0.00)\end{array}$ \\
\hline Age squared & $\begin{array}{l}0.000^{* * * *} \\
(0.00)\end{array}$ & $\begin{array}{l}0.000^{* *} \\
(0.00)\end{array}$ & $\begin{array}{l}0.000^{* * *} \\
(0.00)\end{array}$ & $\begin{array}{l}0.000^{* * *} \\
(0.00)\end{array}$ \\
\hline One Parent Immigrant & $\begin{array}{l}-0.196^{* * *} \\
(0.06)\end{array}$ & $\begin{array}{l}-0.187^{* *} \\
(0.06)\end{array}$ & $\begin{array}{l}-0.183^{* *} \\
(0.06)\end{array}$ & $\begin{array}{l}-0.175^{* *} \\
(0.06)\end{array}$ \\
\hline Both Parents Immigrants & $\begin{array}{l}-0.205^{* * *} \\
(0.05)\end{array}$ & $\begin{array}{c}-0.094 \\
(0.05)\end{array}$ & $\begin{array}{l}-0.192^{* * *} \\
(0.05)\end{array}$ & $\begin{array}{l}-0.097^{*} \\
(0.05)\end{array}$ \\
\hline Married & & $\begin{array}{l}0.101^{* * *} \\
(0.03)\end{array}$ & & $\begin{array}{l}0.121^{* * * *} \\
(0.03)\end{array}$ \\
\hline Divorced & & $\begin{array}{l}-0.097 \\
(0.05)\end{array}$ & & $\begin{array}{l}-0.123^{*} \\
(0.05)\end{array}$ \\
\hline Widowed & & $\begin{array}{l}0.037 \\
(0.05)\end{array}$ & & $\begin{array}{l}0.050 \\
(0.05)\end{array}$ \\
\hline \multicolumn{5}{|l|}{ Primary income source: } \\
\hline Part-time work & & $\begin{array}{l}-0.071 \\
(0.04)\end{array}$ & & $\begin{array}{l}-0.064 \\
(0.04)\end{array}$ \\
\hline Self-employment & & $\begin{array}{l}-0.089^{*} \\
(0.04)\end{array}$ & & $\begin{array}{l}-0.104^{* *} \\
(0.03)\end{array}$ \\
\hline Pension & & $\begin{array}{l}0.075 \\
(0.04)\end{array}$ & & $\begin{array}{l}0.037 \\
(0.04)\end{array}$ \\
\hline Housewife & & $\begin{array}{l}0.017 \\
(0.04)\end{array}$ & & $\begin{array}{l}-0.003 \\
(0.04)\end{array}$ \\
\hline Student & & $\begin{array}{l}0.069 \\
(0.04)\end{array}$ & & $\begin{array}{l}0.063 \\
(0.04)\end{array}$ \\
\hline Unemployment benefits & & $\begin{array}{l}-0.081^{*} \\
(0.04)\end{array}$ & & $\begin{array}{l}-0.108^{* *} \\
(0.04)\end{array}$ \\
\hline Other & & $\begin{array}{l}-0.044 \\
(0.07) \\
\end{array}$ & & $\begin{array}{r}-0.080 \\
(0.06) \\
\end{array}$ \\
\hline Bayesian Information Criterion & 61,509 & 59,043 & 87,559 & 84,618 \\
\hline Observations & 53,592 & 51,483 & 53,592 & 51,483 \\
\hline
\end{tabular}

Note: All regressions include country dummies. 


\section{Conclusion}

Interpersonal relations are embedded in the judgements associated with the social categories that individuals perceive in their fellow human beings. The nature of those judgments can be explained by a theory of symbolic values where agents, e.g. parents, rationally shape individual value systems under some constraints. Using that theoretical framework, I have developed a simple model of relations between natives and immigrants where value of own nationality and disvalue of different ethnicity are endogenously determined. In that model, the formation of value associated with the inherited ethnic trait interacts with the transmission of value attached to an endogenous achievement trait. Values generate economic incentives and are affected by them. Individuals who are less likely to achieve are predicted to invest more value on nationalism and to have hostile relations with immigrants. Multiple equilibria are possible and more effective schooling may eliminate equilibria with xenophobia. Econometric findings from three large surveys corroborate the predictions derived from the theoretical model about the relationship between ability and nationalism.

Differently from the US, there is no "European dream" on which European countries can rely to foster the assimilation of immigrants into their societies. This does not mean that immigrants in Europe are condemned to live apart from the rest of society - like the black population that lives in US ghettos. Between assimilation and ghettization there exists a whole spectrum of social interactions between natives and immigrants characterized by some integration of the two groups. Integration is a two-sided process. A prerequisite of it is some mutual respect of the identity of the other group. Without mutual esteem, spatial and social segregation are likely to persist. This paper has argued that the improvement of human abilities through better schools has a positive impact on mutual respect and contributes to reduce interethnic conflict. The argument does not rely upon a Victorian view of schools as intruments to improve character, but on the self-interest of agents who socialize their children. The novel idea put forward by the model is that investing resources to increase the cognitive ability of low-ability natives may improve the integration of immigrants in society. Such an investment is predicted to induce parents of low-ability children to raise their children's perseverance and conscientiousness and to

avoid boosting their self-esteem by transmitting a feeling of national or racial superiority. In turn, this social change of values will strenghten the incentive for immigrants to invest in their and their children's human capital. 


\section{APPENDIX}

Proof of Proposition 1: Since parents' and children's interests are perfecty aligned and their information sets are identical, an agent's optimal strategy simply is to maximize (4) with respect to the three control variables $e, \delta_{n}$ and $\delta_{a}$. To begin with, notice that the optimal strategy entails $\delta_{n}^{*} \geq 0$ for a domestic citizen $\left(\delta_{n}^{*} \leq 0\right.$ for an immigrant). Suppose by way of contradiction that the optimal socialization of a domestic citizen entails $\delta_{n}^{*}<0$. Starting from such a situation, a marginal increase in nationalism affects expected utility as follows

$$
\frac{\partial E[U]}{\partial \delta_{n}}=\beta-\frac{\delta_{n}^{*}}{\eta}+\frac{\left|\delta_{a}^{*}\right|-\delta_{n}^{*}}{\sigma}>0,
$$

which contradicts the assertion that $\delta_{n}^{*}<0$.

The four mutually exclusive possible solutions are as follows.

Configuration 1: $\delta_{n}^{*}>0, \delta_{a}^{*}<0, e^{*}=0$.

The FOCs are in this case:

$$
\begin{gathered}
\frac{\partial E[U]}{\partial \delta_{a}}=(2 \pi-1) \beta-\frac{\delta_{a}^{*}}{\alpha}+\frac{\delta_{n}^{*}-\delta_{a}^{*}}{\sigma}=0, \\
\frac{\partial E[U]}{\partial \delta_{n}}=\beta-\frac{\delta_{n}^{*}}{\eta}-\frac{\delta_{n}^{*}-\delta_{a}^{*}}{\sigma}=0,
\end{gathered}
$$

while the corner solution $e^{*}=0$ requires

$$
\left(w_{H}-w_{L}\right)+\beta\left(\widehat{v}_{11}-\widehat{v}_{01}+2 \delta_{a}^{*}\right)+\gamma\left(\operatorname{socv}_{11}-\operatorname{socv}_{01}\right) \leq 0 .
$$

Solving for the FOCs yields:

$$
\begin{gathered}
\delta_{a}^{*}=-\frac{\alpha \beta[(1-2 \pi) \sigma-2 \pi \eta]}{\alpha+\eta+\sigma}, \\
\delta_{n}^{*}=\frac{\beta \eta(\sigma+2 \alpha \pi)}{\alpha+\eta+\sigma} .
\end{gathered}
$$

Configuration 2: $\delta_{n}^{*}>0, \delta_{a}^{*}<0, e^{*}>0$.

The associated FOCs are

$$
\frac{\partial E[U]}{\partial \delta_{a}}=\left[2\left(\pi+\theta e^{*}\right)-1\right] \beta-\frac{\delta_{a}^{*}}{\alpha}+\frac{\delta_{n}^{*}-\delta_{a}^{*}}{\sigma}=0 .
$$

(7) and (5). Solving the equation system yields

$$
e^{*}=\frac{\theta \omega\left\{\left(\Delta w+\beta\left(\widehat{v}_{11}-\widehat{v}_{01}\right)+\gamma \Delta \widehat{s o c v}\right)(\alpha+\eta+\sigma)+2 \alpha \beta^{2}[\eta-(1-2 \pi)(\eta+\sigma)]\right\}}{\alpha+\eta+\sigma-4 \alpha \beta^{2} \theta^{2} \omega(\eta+\sigma)}
$$




$$
\begin{gathered}
\delta_{a}^{*}=-\frac{\alpha \beta\left\{(1-2 \pi) \sigma-2 \pi \eta-2 \omega \theta^{2}\left[\Delta w+\beta\left(\widehat{v}_{11}-\widehat{v}_{01}\right)+\gamma \Delta \widehat{\text { SOCv }}\right](\eta+\sigma)\right\}}{\alpha+\eta+\sigma-4 \alpha \beta^{2} \theta^{2} \omega(\eta+\sigma)} \\
\delta_{n}^{*}=\frac{\beta \eta\left\{\sigma+2 \alpha \pi+2 \alpha \theta^{2} \omega\left[\Delta w+\beta\left(\widehat{v}_{11}-\widehat{v}_{01}\right)+\gamma \Delta \widehat{\text { SOCv }}-2 \beta^{2} \sigma\right]\right\}}{\alpha+\eta+\sigma-4 \alpha \beta^{2} \theta^{2} \omega(\eta+\sigma)} .
\end{gathered}
$$

Configuration 3: $\delta_{n}^{*}>0, \delta_{a}^{*}=0, e^{*}>0$.

The FOCs are (7) and (5). The corner solution $\delta_{a}^{*}=0$ requires

$$
\left[2\left(\pi+\theta e^{*}\right)-1\right] \beta-\frac{\delta_{n}^{*}}{\sigma} \leq 0
$$

and

$$
\left[2\left(\pi+\theta e^{*}\right)-1\right] \beta+\frac{\delta_{n}^{*}}{\sigma} \geq 0 .
$$

The optimal strategy has (5) and

$$
\delta_{n}^{*}=\frac{\beta \eta \sigma}{\eta+\sigma} .
$$

Configuration 4: $\delta_{n}^{*}>0, \delta_{a}^{*}>0, e^{*}>0$.

The FOCs are

$$
\begin{gathered}
\frac{\partial E[U]}{\partial \delta_{a}}=\left[2\left(\pi+\theta e^{*}\right)-1\right] \beta-\frac{\delta_{a}^{*}}{\alpha}-\frac{\delta_{n}^{*}+\delta_{a}^{*}}{\sigma}=0, \\
\frac{\partial E[U]}{\partial \delta_{n}}=\beta-\frac{\delta_{n}^{*}}{\eta}-\frac{\delta_{n}^{*}+\delta_{a}^{*}}{\sigma}=0,
\end{gathered}
$$

and (5). Solving the equation system yields

$$
\begin{gathered}
e^{*}=\frac{\theta \omega\left\{\left(\Delta w+\beta\left(\widehat{v}_{11}-\widehat{v}_{01}\right)+\gamma \Delta \widehat{\operatorname{soc} v}\right)(\alpha+\eta+\sigma)+2 \alpha \beta^{2}[(2 \pi-1)(\eta+\sigma)-\eta]\right\}}{\alpha+\eta+\sigma-4 \alpha \beta^{2} \theta^{2} \omega(\eta+\sigma)} \\
\delta_{a}^{*}=\frac{\alpha \beta\left\{(2 \pi-1)(\eta+\sigma)-\eta+2 \omega \theta^{2}\left[\Delta w+\beta\left(\widehat{v}_{11}-\widehat{v}_{01}\right)+\gamma \Delta \widehat{\operatorname{socv}}\right](\eta+\sigma)\right\}}{\alpha+\eta+\sigma-4 \alpha \beta^{2} \theta^{2} \omega(\eta+\sigma)} \\
\delta_{n}^{*}=\frac{\beta \eta\left\{\sigma+2 \alpha(1-\pi)-2 \alpha \theta^{2} \omega\left[\Delta w+\beta\left(\widehat{v}_{11}-\widehat{v}_{01}\right)+\gamma \Delta \widehat{\text { SOCv }}+2 \beta^{2} \sigma\right]\right\}}{\alpha+\eta+\sigma-4 \alpha \beta^{2} \theta^{2} \omega(\eta+\sigma)} .
\end{gathered}
$$

Simple algebraic manipulations show that the eight remaining possible configurations can never be optimal. QED 
Proof of Proposition 2: Equilibrium existence follows from standard theorems of existence of Nash equilibrium for nonatomic games, see e.g. Rath (1992). Equilibrium multiplicity can be ruled out for $\gamma=0$, while standard social-multiplier arguments show that for $\gamma$ sufficiently large multiple equilibria arise. QED

Proof of Proposition 3: For later use, define

$$
\Gamma \equiv w_{H}-w_{L}+\beta\left(\widehat{v}_{11}-\widehat{v}_{01}\right)+\gamma\left(\operatorname{socv}_{11}-\operatorname{socv}_{01}\right)
$$

and denote by

$$
\Theta \equiv \frac{\alpha+\eta+\sigma}{4 \alpha \beta^{2} \omega(\eta+\sigma)}
$$

the largest possible value of $\theta^{2}$.

Configuration 1: Parameter restrictions are necessary to guarantee $\delta_{a}^{*}<0$ and $e^{*}=$ 0 . If $\Gamma>0$, the condition for $e^{*}=0$ is necessary and sufficient for the existence of configuration 1 ; it can be written as

$$
\pi \leq \frac{2 \alpha \beta^{2} \sigma-(\alpha+\eta+\sigma) \Gamma}{4 \alpha \beta^{2}(\eta+\sigma)} \equiv \pi_{1} .
$$

This configuration only exists if $\pi_{1}>0$, which is assumed to be the case. By differentiating (8) one obtains $\partial \delta_{n}^{*} / \partial \pi>0$.

Configuration 2: It is easy to check that the parameter restriction that implies $e^{*}>0$ also guarantees $\delta_{n}^{*}>0$. That restriction is

$$
\pi>\pi_{1} .
$$

In order for configuration 2 to exist, parameters must also guarantee $\delta_{a}^{*}<0$. This condition can be written as

$$
\pi<\frac{\sigma-2 \theta^{2} \omega(\eta+\sigma) \Gamma}{2(\eta+\sigma)} \equiv \pi_{2}\left(\theta^{2}\right) .
$$

As it is easily checked, $\pi_{2}\left(\theta^{2}\right)>\pi_{1}$ if $\theta^{2} \in(0, \Theta)$ and $\pi_{2}(\Theta)=\pi_{1}$, which shows that configuration 2 occurs if $\pi_{1}<\pi<\pi_{2}\left(\theta^{2}\right)$. By differentiating (10) one obtains $\partial \delta_{n}^{*} / \partial \pi>0$.

Configuration 3: Parameter restrictions are only required to ensure that $\delta_{a}^{*}=0$. Condition (12) is equivalent to

$$
\pi \geq \pi_{2}\left(\theta^{2}\right)
$$

Condition (11) is equivalent to 


$$
\pi \leq \frac{\sigma+2 \eta-2 \theta^{2} \omega(\eta+\sigma) \Gamma}{2(\eta+\sigma)} \equiv \pi_{3}\left(\theta^{2}\right) .
$$

As it is easily checked, $\pi_{3}\left(\theta^{2}\right)>\pi_{2}\left(\theta^{2}\right)$, which shows that configuration 3 occurs if $\pi_{2}\left(\theta^{2}\right) \leq$ $\pi \leq \pi_{3}\left(\theta^{2}\right)$. By differentiating (13) one obtains $\partial \delta_{n}^{*} / \partial \pi=0$.

Configuration 4: The parameter restriction for $\delta_{a}^{*}>0$ automatically implies $e^{*}>0$. Condition $\delta_{a}^{*}>0$ is equivalent to

$$
\pi>\pi_{3}\left(\theta^{2}\right)
$$

The equilibrium condition $\delta_{n}^{*}>0$ requires

$$
\pi<\frac{\sigma+2 \alpha-2 \alpha \theta^{2} \omega \Gamma-4 \alpha \beta^{2} \sigma \theta^{2} \omega}{2} \equiv \pi_{4}\left(\theta^{2}\right) .
$$

As it is easily checked, $\pi_{4}\left(\theta^{2}\right)>\pi_{3}\left(\theta^{2}\right)$ if $\theta^{2} \in(0, \Theta)$ and $\pi_{4}(\Theta)=\pi_{3}(\Theta)$, which shows that configuration 4 occurs if $\pi_{3}(\Theta)<\pi<\pi_{4}\left(\theta^{2}\right)$. By differentiating (16) one obtains $\partial \delta_{n}^{*} / \partial \pi<0$

\section{QED}




\section{References}

Anderson, E., 1999, Code of the Streets, Harvard University Press: Harvard.

Bisin, A. and T. Verdier, 1998, On the Cultural Transmission of Preferences for Social Status, Journal of Public Economics 70, 75-97.

Bisin, A. and T. Verdier, 2000, Beyond the Melting Pot: Cultural Transmission, Marriage, and the Evolution of Ethnic and Religious Traits, Quarterly Journal of Economics 115, 955-988.

Bisin, A., Patacchini, E., Verdier, T. and Y. Zenou, 2008, "Bend It Like Beckham": Ethnic Identity and Integration, mimeo.

Card, D., Dustmann, C. and I. Preston, 2009, Immigration, Wages, and Compositional Amenities: Modeling Variation in Attitudes to Immigration, mimeo.

Corneo, G. and O. Jeanne, 2009a, Symbolic Values, Occupational Choice, and Economic Development, European Economic Review, forthcoming.

Corneo, G. and O. Jeanne, 2009b, A Theory of Tolerance, Journal of Public Economics 93, 691-702.

Cunha, F. and J. Heckman, 2009, The Economics and Psychology of Inequality and Human Development, IZA DP No. 4001.

de Figueiredo, R. and Z. Elkins, 2003, Are Patriots Bigots? An Inquiry into the Vices of In-Group Pride, American Journal of Political Science 47, 171-188.

Della Giusta, M. and N. Hashimzade, 2009, Schooling and Intergenerational Transmission of Values, mimeo.

Fershtman, C. and U. Gneezy, 2001, Discrimination in a Segmented Society: An Experimental Approach, Quarterly Journal of Economics 116, 351-77.

Gui, B., 2005, From Transactions to Encounters: The Joint Generation of Relational Goods and Conventional Values, in Gui, B. and R. Sugden (Eds.), Economics and Social Interactions, Cambridge University Press: Cambridge.

Rath, K., 1992, A Direct Proof of the Existence of Pure Strategy Equilibria in Games with a Continuum of Players, Economic Theory 3, 427-33. 
Roemer, J. and K. Van der Straeten, 2005, Xenophobia and the Size of the Public Sector in France: A Politico-economic Analysis, Journal of Economics 86, 95-144.

Siedler, T., 2008, Parental Unemployment and Young People's Right-Wing Extremism, mimeo. 